Research Article

\title{
Characterization and Potential Antidiabetic Activity of Proanthocyanidins from the Barks of Acacia mangium and Larix gmelinii
}

\author{
X. Chen, ${ }^{1}$ J. Xiong, ${ }^{2}$ Q. He, ${ }^{1}$ and F. Wang $\mathbb{D}^{1}$ \\ ${ }^{1}$ College of Chemical Engineering, Nanjing Forestry University, Jiangsu Key Lab for the Chemistry and \\ Utilization of Agro-Forest Biomass, Nanjing 210037, China \\ ${ }^{2}$ Plants for Human Health Institute, Food Bioprocessing and Nutrition Sciences Department, \\ North Carolina State University, North Carolina Research Campus, Kannapolis, NC 28081, USA \\ Correspondence should be addressed to F. Wang; hgwf@njfu.edu.cn
}

Received 19 October 2018; Revised 11 December 2018; Accepted 22 January 2019; Published 3 March 2019

Academic Editor: Luqman C. Abdullah

Copyright ( 92019 X. Chen et al. This is an open access article distributed under the Creative Commons Attribution License, which permits unrestricted use, distribution, and reproduction in any medium, provided the original work is properly cited.

\begin{abstract}
Proanthocyanidins in ethanol extracts from the barks of Acacia mangium and Larix gmelinii were analyzed by gel permeation chromatography, MALDI-TOF/TOF MS, and HPLC/MS. The inhibitory effects of proanthocyanidins and acid-catalyzed hydrolysis of proanthocyanidins against carbolytic enzymes were also tested. A significant relationship between carbolytic enzymes inhibition and degree of polymerization was established, showing that the degree of polymerization is a major contributor to the biological activity of the proanthocyanidins from both types of woody plant bark. The results indicate that proanthocyanidins from the barks of A. mangium and L. gmelinii have potential antidiabetic properties.
\end{abstract}

\section{Introduction}

Proanthocyanidins (PAs), also known as condensed tannins, are widely distributed in almost all plant-based foods and beverages and are comprised of oligomerized/polymerized flavan-3-ol monomer units [1] with molecular weights between 500 and $30000 \mathrm{Da}$ [2]. The monomeric flavanols differ in their hydroxylation patterns and stereochemistry at C-3. The most common monomers are the diastereomers $(+)$-catechin/ (-)-epicatechin, (-)-gallocatechin/(-)-epigallocatechin, and $(+)$-afzelechin/(-)-epiafzelechin, and their respective oligomeric components and polymers are called procyanidins, prodelphinidins, and propelargonidins [2]. Flavanol monomers are usually linked by C4-C6 or C4-C8 bonds (B-type $\mathrm{PAs})$. In some plants, compounds with an additional C2-C7 ether linkage can occur (A-type PAs). The degree of polymerization (DP) varies over a broad range, from dimers up to about 200 monomeric units [3]. For extracts rich in procyanidins, propelargonidins, and prodelphinidins, their DP and types of flavanols can be analyzed by using the method of acid-catalyzed hydrolysis in the presence of excess phloroglucinol, and the reaction mechanism is displayed in Figure 1 [4]. For extracts rich in some uncommon PAs such as profisetinidin and prorobinetinidin, their DP are usually analyzed by using MALDI-TOF/MS and gel permeation chromatography for that interflavanyl bond of profisetinidin and prorobinetinidin is stable in acid hydrolysis [5]. Owing to the special antioxidant properties and other physiological activities of PAs, known to reduce risk factors associated with certain types of diseases, the chemical connectivity and biological activities of PAs have been extensively studied $[1,6-8]$.

Acacia mangium bark extracts (ABE) and Larix gmelinii bark extracts (LBE) can be used to produce tanned leather base on the PAs-protein interaction, which transforms biodegradable raw hide into leather [9-11]. Moreover, many scholars have attempted to explain their chemical structures and biological activities of PAs $[6,9,10,12]$. Large quantities of L. gmelinii and A. mangium barks, which are rich in PAs, are currently being wasted in China. In early stage, we have 


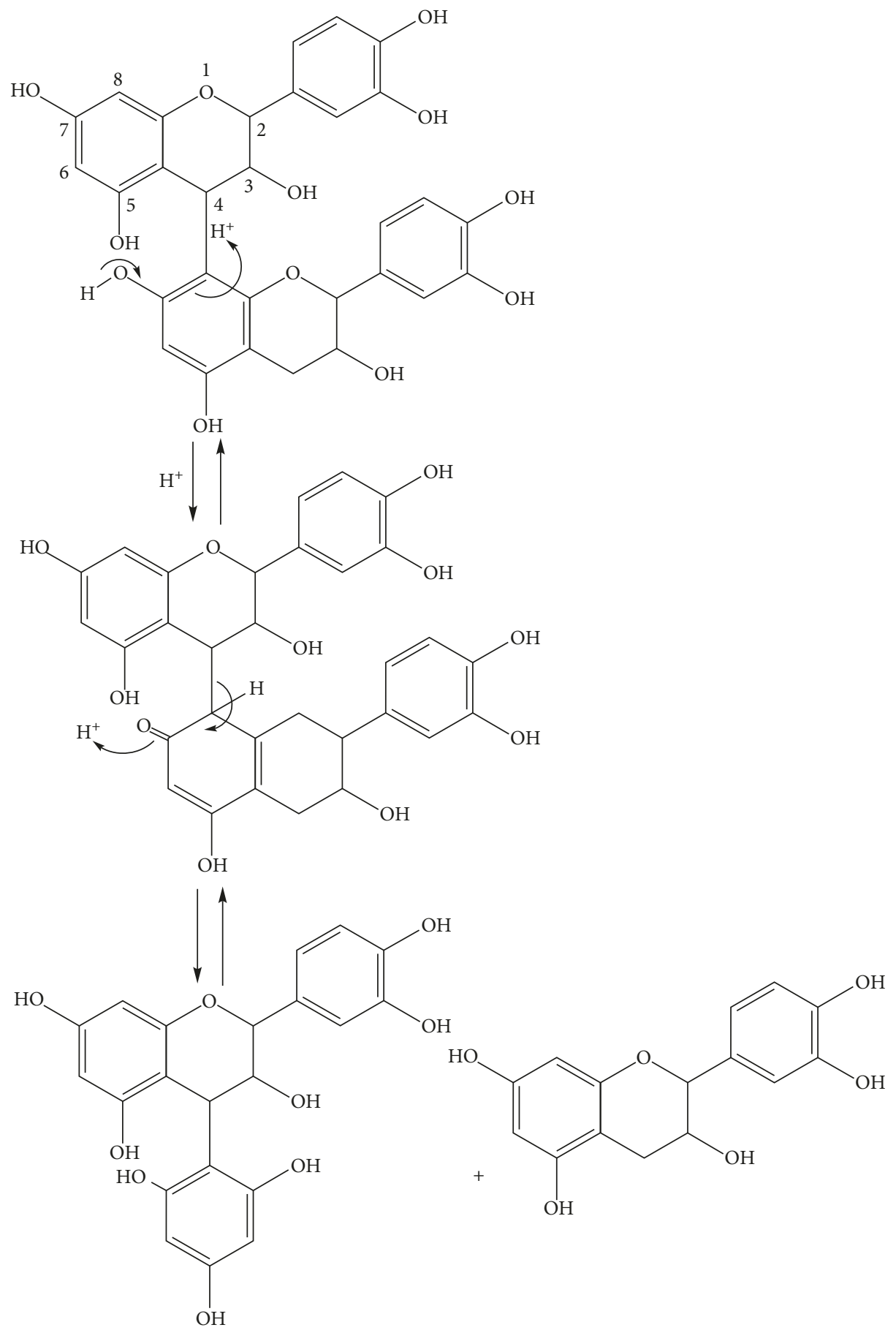

Figure 1: Reaction mechanism of acid-catalyzed hydrolysis in the presence of excess phloroglucinol.

detected the inhibitory effects of Acacia mearnsii PAs on carbolytic enzymes, results proved that Acacia mearnsii PAs with the low DP ranging from 1 to 11 exhibited a stronger inhibition against $\alpha$-glucosidase and a mild inhibition on $\alpha$-amylase, we could just find that PAs inhibited $\alpha$-amylase might dominantly due to its DP, and we could not conclude if the DP of PAs play a predominant role on $\alpha$-glucosidase inhibition [5]. Therefore, the purpose of this study was to characterize PAs in crude ethanol extracts from the barks of L. gmelinii and A. mangium and determine the inhibition of
PAs and acid-catalyzed hydrolysis of PAs on carbolytic enzymes. By using these methods to further verify our previous deduction, the relationship between inhibitory effects on $\alpha$-glucosidase and DP was found. At the same time, resources might be utilized comprehensively.

\section{Materials and Methods}

2.1. Materials. Bark from A. mangium was obtained from Crown Forest Farm in Guangxi Province, China (latitude: 
$24^{\circ} 40^{\prime} 19.41^{\prime \prime} \mathrm{N}$; longitude: $109^{\circ} 45^{\prime} 35.65^{\prime \prime} \mathrm{E}$ ), and bark from L. gmelinii was harvested from the Greater Khingan Mountains in Heilongjiang, China (latitude: $47^{\circ} 27^{\prime} 73.82^{\prime \prime}$ $\mathrm{N}$; longitude: $\left.122^{\circ} 51^{\prime} 36.82^{\prime \prime} \mathrm{E}\right)$. (+)-Catechin, (-)-epicatechin, $\alpha$-amylase (type VI-B, from porcine pancreas), acarbose, $\alpha$-glucosidase (from $S$. cerevisiae), phloroglucinol, $L$-ascorbic acid, and $p$-nitrophenyl- $\alpha$ - $D$-glucopyranoside (pNPG) were purchased from Sigma-Aldrich (St. Louis, MO, USA). Trifluoroacetic acid (TFA) and gallic acid were obtained from Macklin (Shanghai, China). Tetrahydrofuran and methanol (both chromatographically pure) were acquired from Tedia (Fairfield, OH, USA). All other reagents used were of analytical grade.

2.2. Sample Preparation. The dried barks were ground in a small industrial pulverizer, and the powder was passed through a 5 -mesh sieve with $4 \mathrm{~mm}$ openings. Then, $25 \mathrm{~g}$ of the resulting power was defatted twice with hexane $(1: 5$, $\mathrm{w} / \mathrm{v}$ ) and stirred at $300 \mathrm{rpm}$. Defatted barks were resuspended in $50 \%$ ethanol $(375 \mathrm{~mL})$, and then ultrasonicassisted extraction was performed for $30 \mathrm{~min}$ at $50^{\circ} \mathrm{C}$. Two extractions were performed for each sample, the combined solution was evaporated, and remaining aqueous phase was lyophilized to afford $\mathrm{ABE}$ and $\mathrm{LBE}$. The acquired extracts were freshly dissolved in dimethyl sulfoxide as a $50 \mathrm{mg} / \mathrm{mL}$ as the stock solution and diluted with water or sodium phosphate buffer for total polyphenol content (TPC) and carbolytic enzymes inhibition analyses.

2.3. HPLC/MS Analysis. The HPLC/MS analysis was conducted as our previous work with some modifications [5]. The modification was that we used an Agilent 1260 Diode Array Detector HPLC platform connected with a Agilent 6130 MS to tentatively identify PAs using the combination of MS and UV-visible spectra.

\subsection{MALDI-TOF/TOF MS and Gel Permeation Chromatog-} raphy (GPC) Analysis of PAs. The MALDI-TOF mass spectrometry was performed on a MALDI-TOF instrument (UltrafleXtreme, Bruker, German). The parameter setting was detailed in our previously published protocols [5]. Identities of the compounds were determined by comparing the observed $[\mathrm{M}+\mathrm{Na}]^{+}$with theoretical values calculated using the following formula [13]:

$$
\begin{aligned}
{[\mathrm{M}+\mathrm{Na}]^{+}=} & 290.08 \times(\mathrm{EC} / \mathrm{R})+274.08 \times F+306.07 \times \mathrm{EGC} \\
& +152.01 \times \mathrm{GAL}-2.02 \times B-4.04 \times A+22.99
\end{aligned}
$$

where EC, $R, F, \mathrm{EGC}$, and GAL correspond to the number of (epi)catechin, robinetinidol, fisetinidol, (epi)gallocatechin, and galloyl moieties, respectively, and $A$ and $B$ represent the number of $A$ and $B$ linkages.

Gel permeation chromatography (GPC) was performed to verify the molecular weight (MW) of PAs in the extracts. The GPC analysis was conducted using a Waters 1515 HPLC system with a UV detector at $280 \mathrm{~nm}$. A $10 \mu \mathrm{m}$ Styragel HT 3 column (i.d., $300 \times 7.8 \mathrm{~mm}$; Waters, Florida, USA) and a $10 \mu \mathrm{m}$ Styragel HT 4 column (i.d., $300 \times 7.8 \mathrm{~mm}$; Waters) were connected in series. The extracts were firstly dissolved in tetrahydrofuran (about $5 \mathrm{mg} / \mathrm{mL}$ ), separations and analysis were conducted as our previous protocols [14].

2.5. Total Polyphenol Content (TPC). The TPC was measured using the Folin-Ciocalteu assay as our previously published methods $[14,15]$. Results are presented as milligrams gallic acid equivalent (GAE)/g of dried extract.

2.6. Acid Catalysis of PAs in the Presence of Excess Phloroglucinol. ABE or LBE $(100 \mathrm{mg})$ was dissolved in $20 \mathrm{~mL}$ of freshly prepared methanol solution consisting of $0.2 \mathrm{~N} \mathrm{HCl}, 50 \mathrm{~g} / \mathrm{L}$ phloroglucinol, and $10 \mathrm{~g} / \mathrm{L}$ ascorbic acid [16]. The solution was maintained at $55^{\circ} \mathrm{C}$ for $30 \mathrm{~min}$ to allow the reaction to proceed, and the reaction stopped by adding an equal volume of $200 \mathrm{mM}$ aqueous sodium acetate. Then, the organic solvent was removed by evaporation. Finally, the acid-catalyzed hydrolysis PA solutions were lyophilized. The lyophilized samples were dissolved in dimethyl sulfoxide as a $250 \mathrm{mg} / \mathrm{mL}$ stock solution and diluted in sodium phosphate buffer for carbolytic enzymes inhibition analyses.

2.7. Carbolytic Enzyme Inhibition. $\alpha$-Amylase and $\alpha$-glucosidase are the important enzymes associated with type 2 diabetes mellitus, and consequently, inhibition of these enzymes is postulated to be a preventive treatment among currently available antidiabetic therapeutic methods [17]. The inhibitory effects of both bark extracts on $\alpha$-amylase were performed using turbidity measurements, and details of the procedures were provided in our previously published methods [5]. The percentage of inhibition was calculated using the following equation:

$$
\text { inhibition }(\%)=\left[\frac{\left(\mathrm{AUC}_{\mathrm{S}}-\mathrm{AUC}_{\mathrm{C}}\right)}{\mathrm{AUC}_{\mathrm{S}}}\right] \times 100 \text {, }
$$

where $\mathrm{AUC}_{S}$ is the area under the inhibitory curve and $\mathrm{AUC}_{\mathrm{C}}$ is the area under the control curve. $\mathrm{IC}_{50}$ can be defined as the concentration of inhibitor that produces $50 \%$ inhibition of enzyme activity under a specified condition and was determined by linear interpolation of the percentage of inhibition using an inhibitor concentration curve.

The inhibitory effects on $\alpha$-glucosidase were assayed using our previously described method $[5,14]$. The absorbance was read at $405 \mathrm{~nm}$, and results were calculated using the following equation:

$$
\text { inhibition }(\%)=\left[\frac{\left(A_{\mathrm{C}}-A_{\mathrm{S}}\right)}{A_{\mathrm{C}}}\right] \times 100,
$$

where $A_{\mathrm{C}}$ denotes the control sample absorbance and $A_{\mathrm{S}}$ denotes the sample absorbance. Results are expressed as the sample concentration $(\mu \mathrm{g} / \mathrm{mL})$ required to inhibit $50 \%$ of the enzyme activity $\left(\mathrm{IC}_{50}\right)$. 
2.8. Statistical Analysis. Samples were analyzed in triplicate. All data are expressed as mean \pm one standard deviation (SD). Statistical analyses were performed using Origin software (OriginLab, Northampton, MA, USA).

\section{Results and Discussion}

3.1. HPLC/MS Analysis. Oligomeric PAs in ABE and LBE were identified by conducting a reversed-phase HPLC analysis. Peaks under different retention times of HPLC were identified using MS and UV-visible spectra. Results of mass spectrometry are presented in the supplementary materials (Figures S1-S2). As shown in Table 1, 12 components were found to be present in the extracts and tentatively identified as monomers, dimers, and trimers. Since catechin and epicatechin (Figure 2(a)) were detected in LBE, the peaks associated with the LBE group were separated by intervals of $\mathrm{m} / z 288$, corresponding to the incremental mass of (epi) catechin extension. Peaks associated with the ABE groups were separated by intervals of $m / z 272, m / z 288$, and $m / z 304$, corresponding to the incremental mass of (epi)fisetinidol (Figure 2(b)), (epi)robinetinidol (Figure 2(c)), and (epi) gallocatechin (Figure 2(d)), respectively [18]. We did not detect any PAs with DP greater than 3 in both bark extracts, which may be due to the fact that ESI works poorly for detecting PAs with a higher molecular weight [13]. All the PAs detected in Table 1 were B-type linkages and some of them were isomers. Chemical connectivity of the various isomers was not determined.

3.2. MALDI-TOF/TOF MS and GPC Analysis of PAs. Because larger PAs were found difficult to be detected by ESI, we used MALDI-TOF/TOF MS to identify PAs with a DP greater than three. Figures S3 and S4 show the MALDI-TOF positive-ion reflectron mode mass spectra of PAs in $\mathrm{ABE}$ and $\mathrm{LBE}$ recorded as sodium adduct ions.

As shown in Table 2, all PAs in LBE appeared to consist of (epi)catechin and (epi)gallocatechin, linked through $\mathrm{C}_{4^{-}}$ $\mathrm{C}_{6}$ or $\mathrm{C}_{4}-\mathrm{C}_{8}$ bonds. However, PAs from ABE were different and appeared to consist of robinetinidol, fisetinidol, and gallocatechin, possessing $\mathrm{C}_{4}-\mathrm{C}_{6}$ or $\mathrm{C}_{4}-\mathrm{C}_{8}$ linkage. However, we could not deduce the order of linkages. A total of 16 PAs were detected in the extracts (Table 2), corresponding to a wide variety of structures, including trimers to heptamers of procyanidins, prodelphinidins, profisetinidins, and prorobinetinidins with only B-type linkages, one of them galloylated. We did not detect any PAs with a DP greater than seven by MALDI-TOF/TOF MS, perhaps because Na works poorly for PAs with a DP greater than eight [13].

To further determine the properties of PAs in extracts, GPC was used to analyze MW. Results are shown in Figure 3. The maximum MW of $3100 \mathrm{Da}$ was observed among PAs from $\mathrm{ABE}$, which was higher than those of LBE.

3.3. Determination of TPC. The values of TPC varied from 340 (LBE) to 415 (ABE) mg GAE/g of the dried extract. The results indicated that both extracts from woody plant barks are rich in PAs and possess a high polyphenol content.
TABLE 1: Components identified in ABE and LBE by LC/MS.

\begin{tabular}{lccccc}
\hline RT $(\min )$ & MS & Max $(\mathrm{nm})$ & Structure & LBE & ABE \\
\hline 14.0 & 594 & 278 & B dimer & & $\times$ \\
14.4 & 578 & 278 & B dimer & $\times$ & \\
15.6 & 290 & 280 & Catechin & $\times$ & \\
17.1 & 578 & 278 & B dimer & $\times$ & $\times$ \\
17.8 & 578 & 280 & B dimer & $\times$ & \\
19.4 & 882 & 280 & B trimer & & $\times$ \\
20.3 & 290 & 280 & Epicatechin & $\times$ & \\
25.3 & 882 & 278 & B trimer & & $\times$ \\
33.6 & 866 & 278 & B trimer & & $\times$ \\
34.4 & 406 & 256 & Unknown & $\times$ & \\
39.2 & 866 & 278 & B trimer & & $\times$ \\
44.0 & 304 & 258 & Unknown & $\times$ & \\
\hline
\end{tabular}

Boxes with $\times$ indicate that the compound was identified in the sample. Catechin and epicatechin were supported through analysis of standard solutions.

3.4. $\alpha$-Amylase and $\alpha$-Glucosidase Inhibition. As shown in Figure $4, \mathrm{LBE}$ at $40 \mu \mathrm{g} / \mathrm{mL}$ and $\mathrm{ABE}$ at $30 \mu \mathrm{g} / \mathrm{mL}$ can cause obvious inhibitory effects on $\alpha$-amylase. When increasing the concentration to $50 \mu \mathrm{g} / \mathrm{mL}$, more than $70 \%$ inhibition can be achieved. From the dose-response curves (Figure 5(a)), the two plant extracts clearly display inhibitory activity against $\alpha$-amylase, with $\mathrm{IC}_{50}$ values of $29.7 \pm 2.5 \mu \mathrm{g} / \mathrm{mL}$ (LBE) and $19.1 \pm 3.4 \mu \mathrm{g} / \mathrm{mL}$ (ABE). Dose-response curves for $\alpha$-glucosidase inhibition are presented in Figure 5(b). For both extracts, inhibition against $\alpha$-glucosidase is clearly observed, with similar IC $_{50}$ of about $10.1 \pm 1.9 \mu \mathrm{g} / \mathrm{mL}$ (LBE) and $22.0 \pm 1.7 \mu \mathrm{g} / \mathrm{mL}(\mathrm{ABE})$. As a reference, inhibition by acarbose displayed in Figure 6 was measured under the same conditions, and the $\mathrm{IC}_{50}$ values were calculated as $8.25 \pm 4.3$ and $164.21 \pm 3.5 \mu \mathrm{g} / \mathrm{mL}$ for $\alpha$-amylase and $\alpha$-glucosidase, respectively. These values are very similar to those presented in previously published works $[5,19,20]$. For convenient comparison, both plant extracts exhibited mild $\alpha$-amylase inhibition activity and strong $\alpha$-glucosidase inhibition activity, which could potentially prevent abnormal bacterial fermentation of undigested carbohydrates in the colon [21].

When acid-catalyzed hydrolysis of PAs occurs in the presence of excess phloroglucinol, PAs are decomposed into subunit compositions including terminal subunits, such as flavan-3-ol monomers (catechin or epicatechin), and extension subunits [4]. We also detected inhibitory effects against $\alpha$-amylase and $\alpha$-glucosidase. The results are presented in Figures 7 and 8. After acid-catalyzed hydrolysis of the PAs of LBE, no inhibition against $\alpha$-amylase at high concentrations $(5 \mathrm{mg} / \mathrm{mL}$ ) was observed; however, the starch degradation rate improved, perhaps owing to an increase in the mass transfer effect of some compounds in the sample which increases the likelihood of contact between the $\alpha$-amylase and starch. Furthermore, the results suggest that DP effectively contributes to the inhibition of $\alpha$-amylase. Similar results were previously reported. More specifically, the addition of gelatin to bind and precipitate PAs greatly diminishes inhibitory activity against $\alpha$-amylase [20, 22]. The study also implicated PAs as active substances in LBE. In our study, PAs of acid-catalyzed hydrolysis from ABE showed weaker inhibitory effects against $\alpha$-amylase, 
<smiles>Oc1cc(O)c2c(c1)OC(c1ccc(O)c(O)c1)C(O)C2</smiles>

(a)<smiles>Oc1ccc2c(c1)OC(c1cc(O)c(O)c(O)c1)C(O)C2</smiles>

(c)<smiles>Oc1ccc2c(c1)OC(c1ccc(O)c(O)c1)C(O)C2</smiles>

(b)<smiles>Oc1cc(O)c2c(c1)OC(c1cc(O)c(O)c(O)c1)C(O)C2</smiles>

(d)

FIGURE 2: Chemical structure of (a) (epi)catechin, (b) (epi)fisetinidol, (c) (epi)robinetinidol, and (d) (epi)gallocatechin.

TABLE 2: PAs from ABE and LBE detected by MALDI-TOF/TOF MS.

\begin{tabular}{|c|c|c|c|c|c|c|c|c|c|}
\hline \multirow[b]{2}{*}{ Polymer } & \multirow{2}{*}{$\begin{array}{c}\text { Number of } \\
\text { EC/R }\end{array}$} & \multirow{2}{*}{$\begin{array}{c}\text { Number of } \\
\text { EGC }\end{array}$} & \multirow{2}{*}{$\begin{array}{c}\text { Number } \\
\text { of } F\end{array}$} & \multirow{2}{*}{$\begin{array}{c}\text { Number of } \\
\text { GAL }\end{array}$} & \multirow{2}{*}{$\begin{array}{l}\text { Calculated } \\
{[\mathrm{M}+\mathrm{Na}]^{+}}\end{array}$} & \multicolumn{2}{|c|}{$\mathrm{ABE}$} & \multicolumn{2}{|c|}{ LBE } \\
\hline & & & & & & $\begin{array}{c}\text { Observed } \\
{[\mathrm{M}+\mathrm{Na}]^{+}}\end{array}$ & $\begin{array}{c}\Delta m \\
(\mathrm{ppm})\end{array}$ & $\begin{array}{c}\text { Observed } \\
{[\mathrm{M}+\mathrm{Na}]^{+}}\end{array}$ & $\begin{array}{c}\Delta m \\
(\mathrm{ppm})\end{array}$ \\
\hline \multirow{2}{*}{ Trimer } & 3 & 0 & 0 & 0 & 889.1 & ND & & 889.433 & 374.4 \\
\hline & 3 & 0 & 0 & 1 & 1041.1 & 1040.889 & -202.7 & 1040.963 & -131.6 \\
\hline \multirow{3}{*}{ Tetramer } & 4 & 0 & 0 & 0 & 1177.2 & 1177.485 & 242.0 & 1177.505 & 259.0 \\
\hline & 3 & 1 & 0 & 0 & 1193.2 & 1193.486 & 239.6 & 1191.507 & -1420.9 \\
\hline & 2 & 2 & 0 & 0 & 1209.2 & 1209.484 & 234.8 & 1207.517 & -1393.8 \\
\hline \multirow{3}{*}{ Pentamer } & 5 & 0 & 0 & 0 & 1465.3 & 1465.596 & 202.0 & 1465.621 & 219.0 \\
\hline & 4 & 1 & 0 & 0 & 1481.2 & 1481.597 & 268.0 & 1481.626 & 287.5 \\
\hline & 3 & 2 & 0 & 0 & 1497.2 & 1497.588 & 259.1 & ND & - \\
\hline \multirow{4}{*}{ Hexamer } & 6 & 0 & 0 & 0 & 1753.3 & 1753.717 & 237.8 & 1753.725 & 242.3 \\
\hline & 5 & 1 & 0 & 0 & 1769.3 & 1769.701 & 226.6 & ND & - \\
\hline & 4 & 2 & 0 & 0 & 1785.3 & 1785.697 & 222.3 & ND & - \\
\hline & 3 & 3 & 0 & 0 & 1801.3 & 1800.731 & -316.0 & ND & - \\
\hline \multirow{4}{*}{ Heptamer } & 6 & 0 & 1 & 0 & 2025.3 & 2025.778 & 236.0 & 2022.906 & -1183.4 \\
\hline & 7 & 0 & 0 & 0 & 2041.3 & 2042.808 & 738.2 & 2040.852 & -219.5 \\
\hline & 6 & 1 & 0 & 0 & 2057.3 & 2058.781 & 719.4 & 2056.804 & -241.2 \\
\hline & 5 & 2 & 0 & 0 & 2073.3 & 2073.816 & 248.8 & ND & - \\
\hline
\end{tabular}

EC, R, F, EGC, and GAL are abbreviations of (epi)catechin, robinetinidol, fisetinidol, (epi)gallocatechin, and galloyl moieties. ND means no peaks corresponding to the calculated peaks were observed.

including no inhibition at $0.5 \mathrm{mg} / \mathrm{mL}$ and approximately $62 \%$ inhibition at $1.8 \mathrm{mg} / \mathrm{mL}$. This phenomenon may be the result of PAs degradation in this chemical environment, rendering them unable to fully catalyze. Moreover, profisetinidin, prorobinetinidin, and prodelphinidin were detected in A. mangium using MALDI-TOF/MS [18]. The absence of 5-hydroxy groups in the chain extender units of profisetinidins and prorobinetinidins leads to stable interflavanyl bonds, which prevent acid hydrolysis [5, 7]. After acid-catalyzed hydrolysis of PAs in the presence of excess phloroglucinol, inhibitory effects against $\alpha$-glucosidase were similar. Consequently, we hypothesize that the monomers themselves may possess certain inhibitory effects against $\alpha$-glucosidase.

Here, we confirmed our prediction by determining the inhibitory effects of epicatechin on $\alpha$-glucosidase. The results 


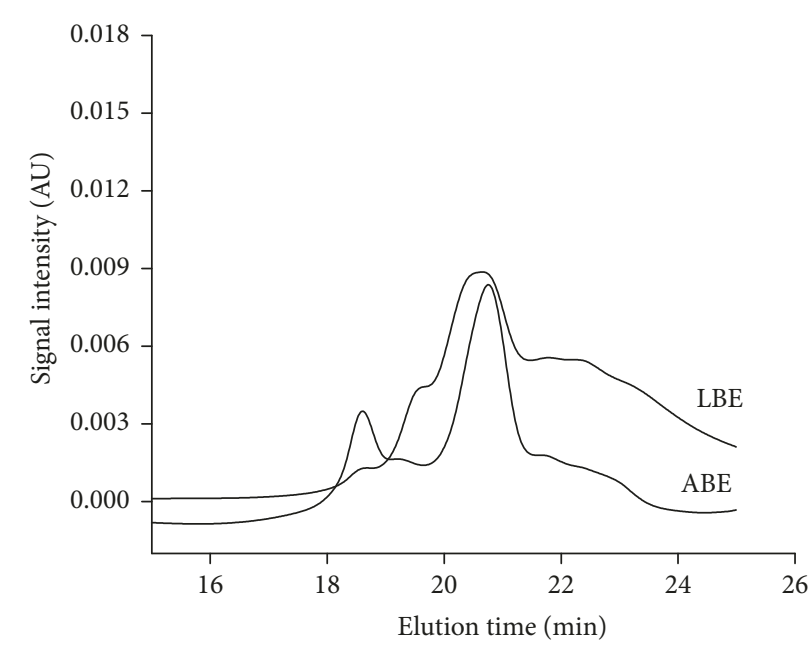

Figure 3: GPC chromatogram of PAs from ABE and LBE.

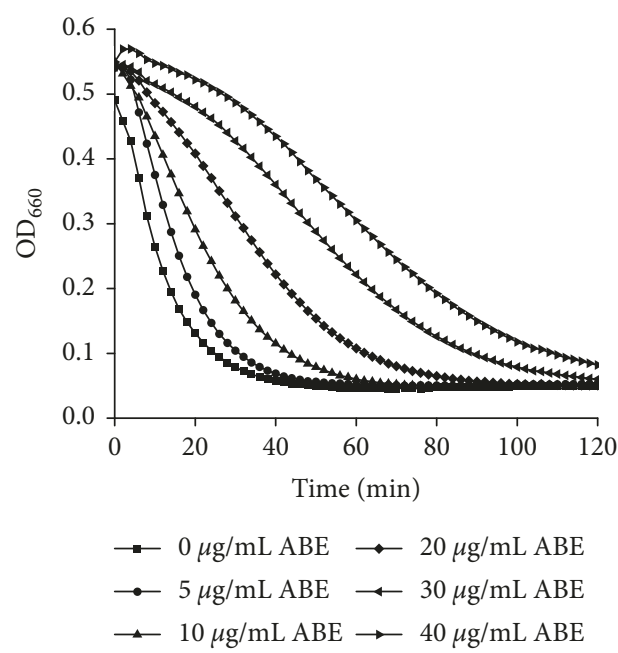

(a)

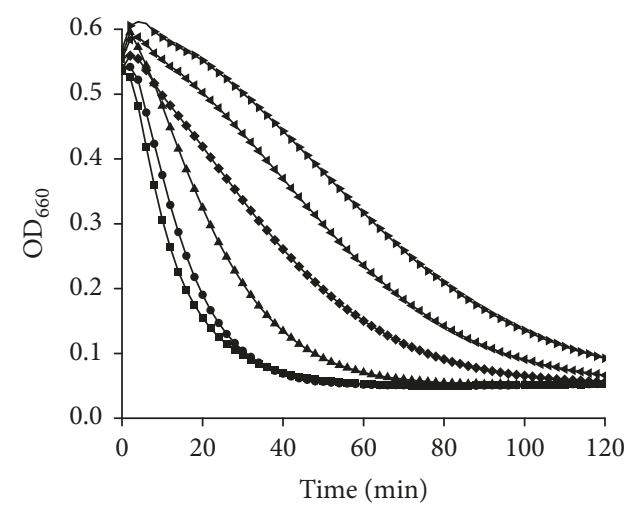

$\rightarrow 0 \mu \mathrm{g} / \mathrm{mL} \mathrm{LBE} \rightarrow 30 \mu \mathrm{g} / \mathrm{mL} \mathrm{LBE}$

$\multimap 10 \mu \mathrm{g} / \mathrm{mL}$ LBE $\longleftarrow 40 \mu \mathrm{g} / \mathrm{mL}$ LBE

$\rightarrow 20 \mu \mathrm{g} / \mathrm{mL} \mathrm{LBE} \rightarrow 50 \mu \mathrm{g} / \mathrm{mL} \mathrm{LBE}$

(b)

FIGURE 4: Kinetic curves of starch hydrolysis by $\alpha$-amylase under different concentrations of the inhibitor.

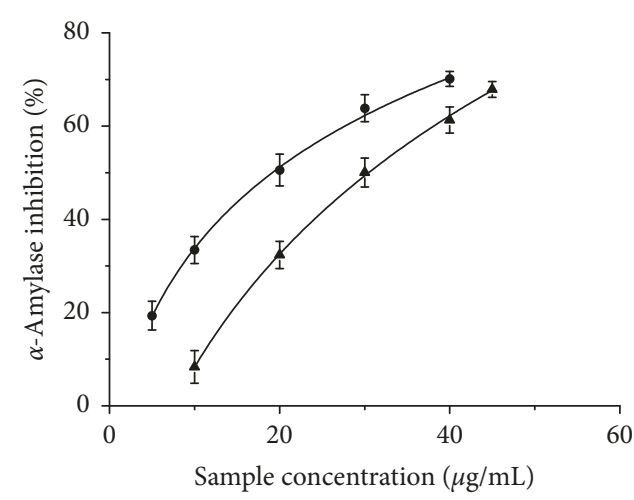

- $\mathrm{ABE}$

$\triangle \mathrm{LBE}$

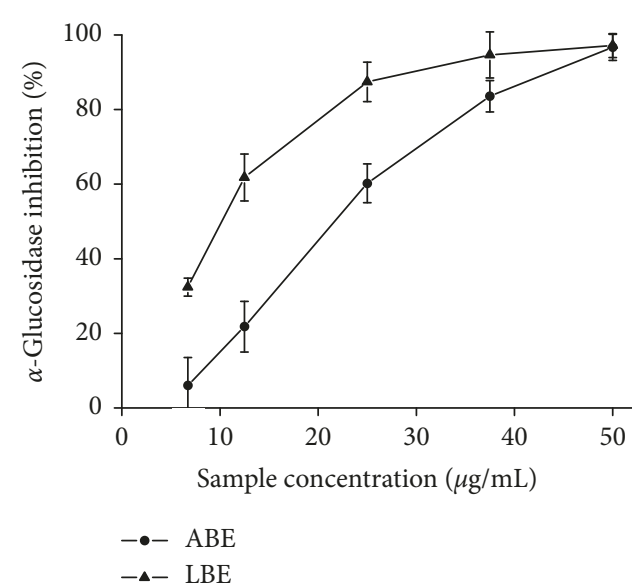

(b)

Figure 5: Dose-response curves of $\alpha$-amylase (a) and $\alpha$-glucosidase (b) inhibitory activities of ABE and LBE. Data are presented as mean \pm one standard deviation. 


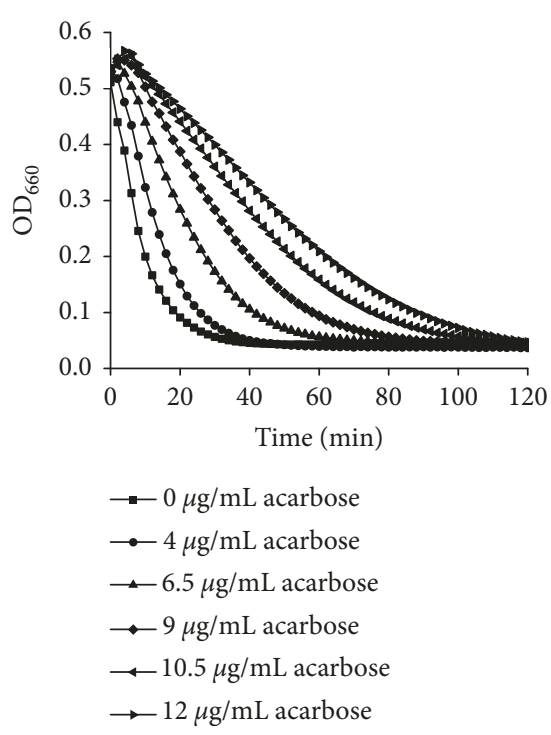

(a)
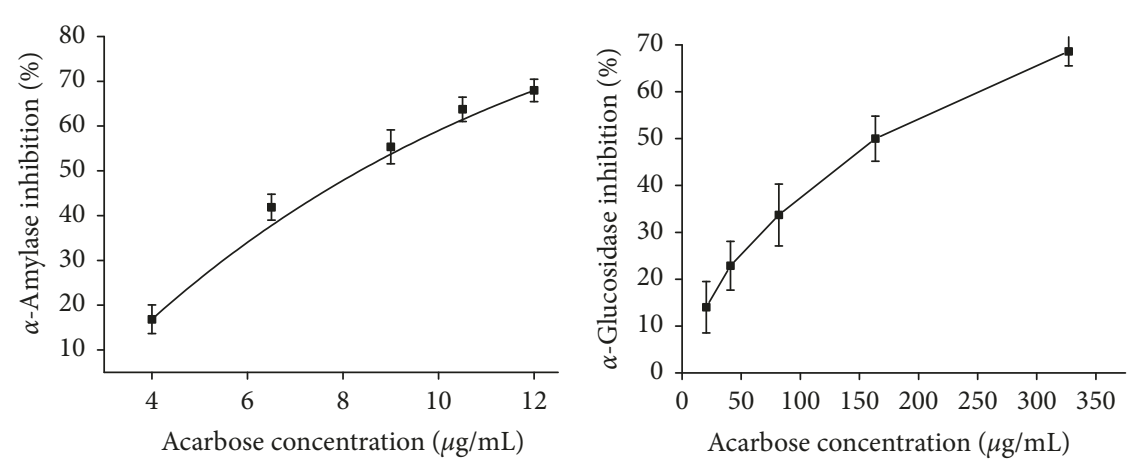

(b) (c)

Figure 6: (a) Kinetic curves of starch hydrolysis by $\alpha$-amylase in the presence of acarbose. Dose-response curves of acarbose for inhibitory activities against $\alpha$-amylase (b) and $\alpha$-glucosidase (c). Data are presented as mean \pm one standard deviation.

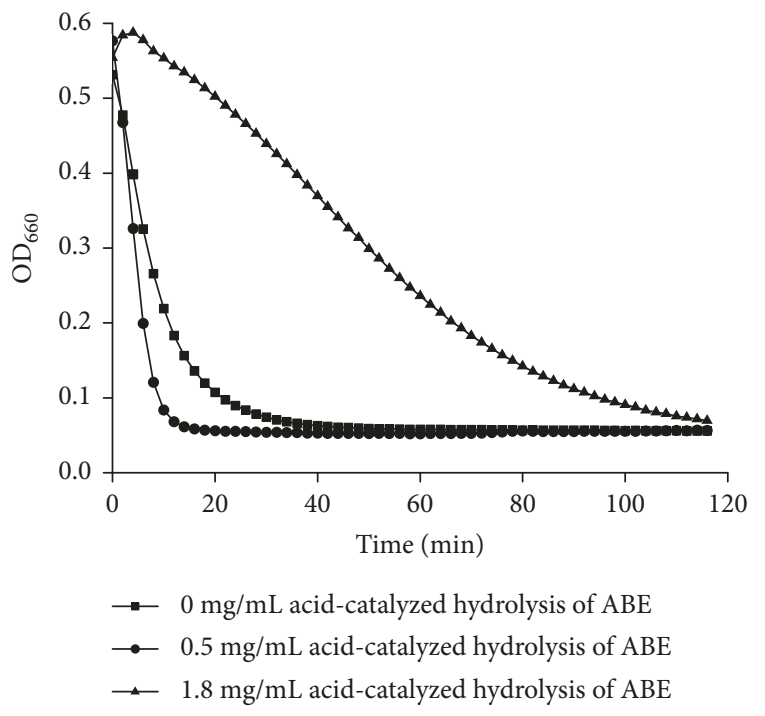

(a)

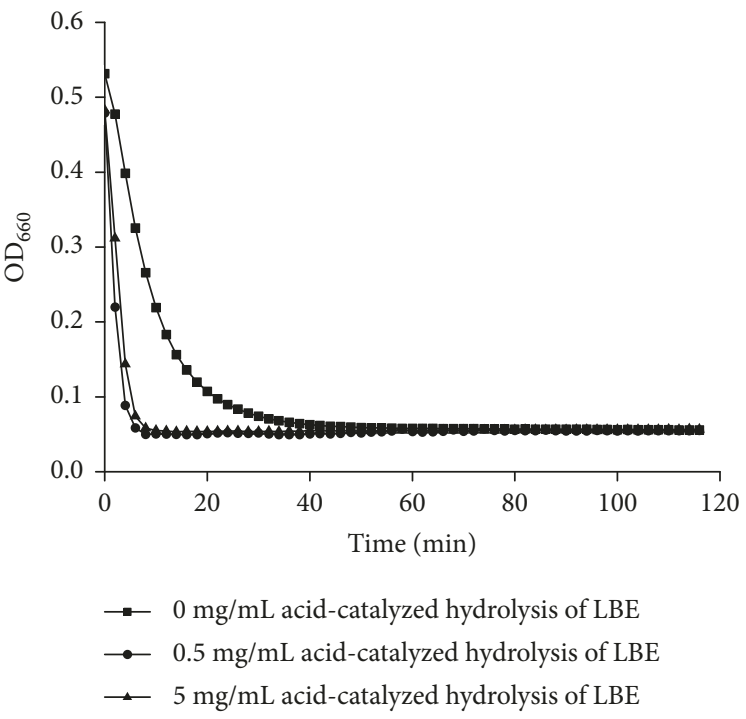

(b)

FIGURE 7: Kinetic curves of starch hydrolysis by $\alpha$-amylase under different concentrations of acid-catalyzed hydrolysis of proanthocyanins from $\mathrm{ABE}$ and LBE.

are displayed in Figure 9. Epicatechin exhibited inhibitory activity against $\alpha$-glucosidase with an $\mathrm{IC}_{50}$ of approximately $200 \pm 3.2 \mu \mathrm{g} / \mathrm{mL}$. The result indicates some inhibitory effects of the monomer against $\alpha$-glucosidase. However, epicatechin cannot be used to confirm prediction that PAs become depolymerized by acid in the presence of excess phloroglucinol, releasing terminal subunits such as flavan-3-ol monomers (catechin and epicatechin) and extension subunits such as electrophilic flavan-3-ol intermediates. The electrophilic intermediates can be trapped by nucleophilic reagents to generate analyzable adducts (Figure 1) [4]. Additionally, flavonoids often exhibit synergistic effects on biological activities
[23]. Based on the inhibitory effects of epicatechin against $\alpha$-glucosidase, the result of DP not playing the predominant role for $\alpha$-glucosidase inhibition was proved, which may also be affected by the nature of interflavanyl bonds of PAs.

\section{Conclusions}

The molecular weights of PAs from the bark of Acacia mangium and Larix gmelinii, ranging from 290 to $2000 \mathrm{Da}$, were detected by MALDI-TOF/TOF MS and HPLC/MS. In addition, the inhibitory activities of both bark extracts against carbolytic enzymes were measured. The results 


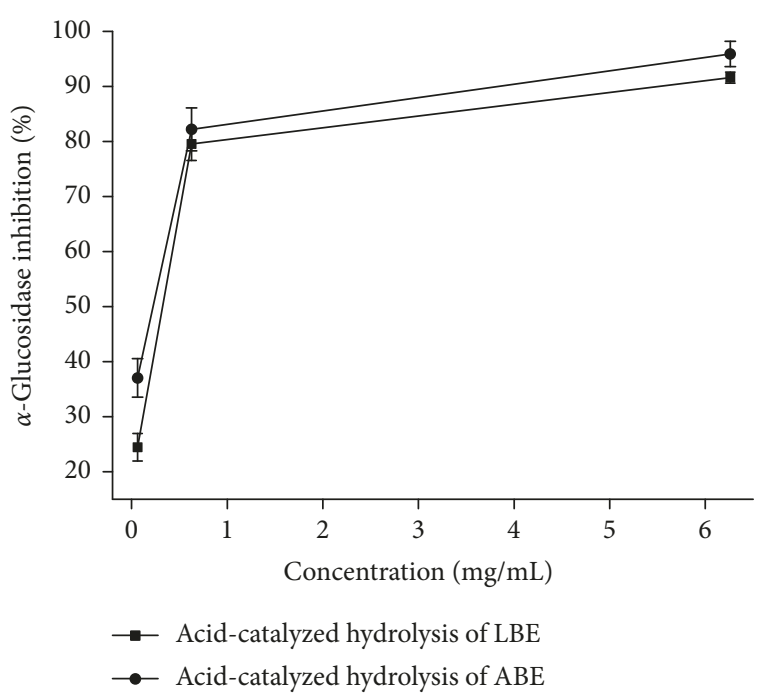

Figure 8: Dose-response curves for $\alpha$-glucosidase inhibitory activity at different concentrations of acid-catalyzed hydrolysis of proanthocyanins from $\mathrm{ABE}$ and LBE. Data are expressed as mean \pm one standard deviation.

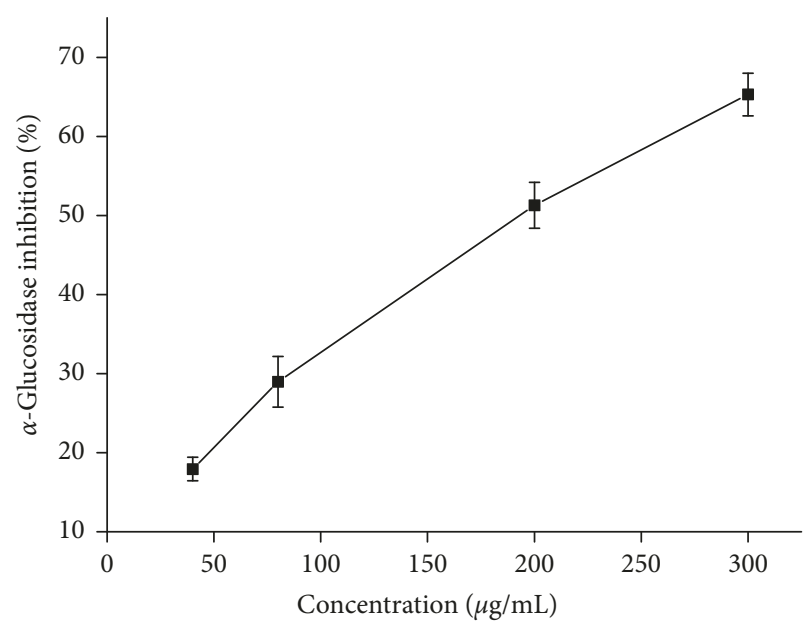

FIGURE 9: Dose-response curve for $\alpha$-glucosidase inhibitory activity of epicatechin. Data are expressed as mean \pm one standard deviation.

demonstrate successful carbolytic enzyme inhibition by PAs. Furthermore, DP of PA was shown to play an important role in the inhibitory effect on $\alpha$-amylase and $\alpha$-glucosidase, but not a predominant role for $\alpha$-glucosidase inhibition. Their potential antidiabetic effects were tentatively investigated. However, further research is still needed to investigate the biological effects of these bioactive compounds in vivo.

\section{Data Availability}

The data used to support the findings of this study are included within the article.

\section{Conflicts of Interest}

The authors declare that they have no conflicts of interest.

\section{Acknowledgments}

The research was financially supported by the National Key Research and Development Program of China under Grant 2016YFD0600801 and Top-Notch Academic Programs Project of Jiangsu Higher Education Institutions (TAPP) under Grant PPZY2015C221. The Priority Academic Program Development of Jiangsu Higher Education Institutions (PAPD) is warmly acknowledged with thanks.

\section{Supplementary Materials}

Mass spectra identified by HPLC/MS (Figures S1 and S2) and MALDI-TOF/TOF MS (Figures S3 and S4) are available as Supporting Information. (Supplementary Materials)

\section{References}

[1] Y. Zhang, X. Zhou, W. Tao et al., "Antioxidant and antiproliferative activities of proanthocyanidins from Chinese bayberry (Myrica rubra Sieb. et Zucc.) leaves," Journal of Functional Foods, vol. 27, pp. 645-654, 2016.

[2] J. Serrano, R. Puupponenpimiä, A. Dauer, A. M. Aura, and F. Sauracalixto, "Tannins: current knowledge of food sources, intake, bioavailability and biological effects," Molecular Nutrition and Food Research, vol. 53, no. S2, pp. S310-S329, 2009.

[3] C. Manach, A. Scalbert, C. Morand, C. Rémésy, and L. Jiménez, "Polyphenols: food sources and bioavailability," The American Journal of Clinical Nutrition, vol. 79, no. 5, pp. 727-747, 2004.

[4] J. A. Kennedy and G. P. Jones, "Analysis of proanthocyanidin cleavage products following acid-catalysis in the presence of excess phloroglucinol," Journal of Agricultural and Food Chemistry, vol. 49, no. 4, pp. 1740-1746, 2001.

[5] X. Chen, J. Xiong, S. Huang et al., "Analytical profiling of proanthocyanidins from Acacia mearnsii bark and in vitro assessment of antioxidant and antidiabetic potential," Molecules, vol. 23, no. 11, p. 2891, 2018.

[6] J. Xiong, M. H. Graceb, D. Esposito, F. Wang, and M. A. Lila, "Phytochemical characterization and anti-inflammatory properties of Acacia mearnsii leaves," Natural Product Communications, vol. 11, no. 5, pp. 649-653, 2016.

[7] R. Kusano, S. Ogawa, Y. Matsuo, T. Tanaka, Y. Yazaki, and I. Kouno, " $\alpha$-Amylase and lipase inhibitory activity and structural characterization of Acacia bark proanthocyanidins," Journal of Natural Products, vol. 74, no. 2, pp. 119-128, 2011.

[8] X. Shen, Y. Wang, and F. Wang, "Characterisation and biological activities of proanthocyanidins from the barks of Pinus massonian and Acacia mearnsii," Natural Product Research, vol. 24, no. 6, pp. 590-598, 2010.

[9] L. Zhang, J. Chen, Y. Wang, D. Wu, and M. Xu, "Phenolic extracts from Acacia mangium bark and their antioxidant activities," Molecules, vol. 15, no. 5, pp. 3567-3577, 2010.

[10] S. Luo, X. Zhang, X. Zhang, and L. Zhang, "Extraction, identification and antioxidant activity of proanthocyanidins from Larix gmelinii Bark," Natural Product Research, vol. 28, no. 14, pp. 1116-1120, 2014.

[11] P. B. Venter, N. D. Senekal, G. Kemp et al., "Analysis of commercial proanthocyanidins. Part 3: the chemical composition of wattle (Acacia mearnsii) bark extract," Phytochemistry, vol. 83, no. 11, pp. 153-167, 2012. 
[12] J. Xiong, M. H. Grace, D. Esposito, S. Komarnytsky, F. Wang, and M. A. Lila, "Polyphenols isolated from Acacia mearnsii bark with anti-inflammatory and carbolytic enzyme inhibitory activities," Chinese Journal of Natural Medicines, vol. 15, no. 11, pp. 816-824, 2017.

[13] J. Pérez-Jiménez and J. L. Torres, "Analysis of proanthocyanidins in almond blanch water by HPLC-ESI-QqQ-MS/MS and MALDI-TOF/TOF MS," Food Research International, vol. 49, no. 2, pp. 798-806, 2012.

[14] X. Chen, J. Xiong, L. He et al., "Effects of in vitro digestion on the content and biological activity of polyphenols from Acacia mearnsii bark," Molecules, vol. 23, no. 7, p. 1804, 2018.

[15] S. Damiano, M. Forino, A. De, L. A. Vitali, G. Lupidi, and O. Taglialatela-Scafati, "Antioxidant and antibiofilm activities of secondary metabolites from Ziziphus jujuba leaves used for infusion preparation," Food Chemistry, vol. 230, pp. 24-29, 2017.

[16] Q. Li, J. Chen, T. Li et al., "Separation and characterization of polyphenolics from underutilized byproducts of fruit production (Choerospondias axillaris peels): inhibitory activity of proanthocyanidins against glycolysis enzymes," Food and Function, vol. 6, no. 12, pp. 3693-3701, 2015.

[17] M. Rubilar, C. Jara, Y. Poo et al., "Extracts of Maqui (Aristotelia chilensis) and Murta (Ugni molinae Turcz.): sources of antioxidant compounds and $\alpha$-Glucosidase $/ \alpha$-Amylase inhibitors," Journal of Agricultural and Food Chemistry, vol. 59, no. 5, pp. 1630-1637, 2011.

[18] Y. B. Hoong, A. Pizzi, P. M. Tahir, and H. Pasch, "Characterization of Acacia mangium polyflavonoid tannins by MALDI-TOF mass spectrometry and CP-MAS ${ }^{13}$ C NMR," European Polymer Journal, vol. 46, no. 6, pp. 1268-1277, 2010.

[19] Y. Y. Ma, D. G. Zhao, A. Y. Zhou, Y. Zhang, Z. Du, and K. Zhang, " $\alpha$-Glucosidase inhibition and antihyperglycemic activity of phenolics from the flowers of edgeworthia gardneri," Journal of Agricultural and Food Chemistry, vol. 63, no. 37, pp. 8162-8169, 2015.

[20] Y. Zhang, A. I. C. Wong, J. E. Wu, N. B. A. Karim, and D. Huang, "Lepisanthes alata (Malay cherry) leaves are potent inhibitors of starch hydrolases due to proanthocyanidins with high degree of polymerization," Journal of Functional Foods, vol. 25 , pp. 568-578, 2016.

[21] S. Lordan, T. J. Smyth, A. Soler-Vila, C. Stanton, and R. P. Ross, "The $\alpha$-amylase and $\alpha$-glucosidase inhibitory effects of Irish seaweed extracts," Food Chemistry, vol. 141, no. 3, pp. 2170-2176, 2013.

[22] A. P. Neilson, S. F. O'Keefe, and B. W. Bolling, "Highmolecular-weight proanthocyanidins in foods: overcoming analytical challenges in pursuit of novel dietary bioactive components," Annual Review of Food Science and Technology, vol. 7, no. 1, pp. 43-64, 2015.

[23] S. M. Lipson, G. Karalis, L. Karthikeyan et al., "Mechanism of anti-rotavirus synergistic activity by epigallocatechin gallate and a proanthocyanidin-containing nutraceutical," Food and Environmental Virology, vol. 9, no. 4, pp. 434-443, 2017. 

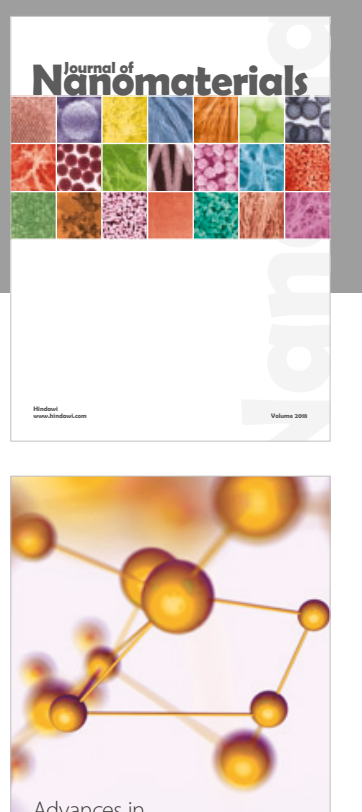

Physical Chemistry
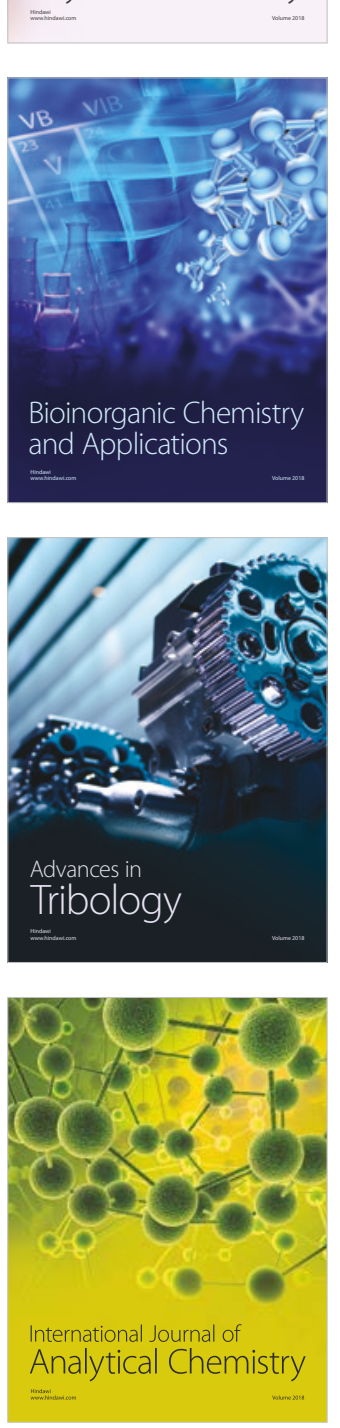

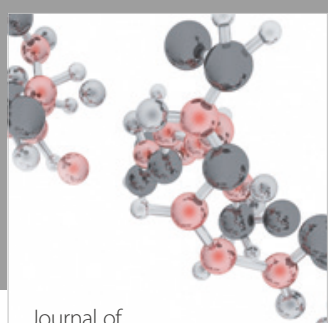

Analytical Methods

in Chemistry

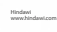

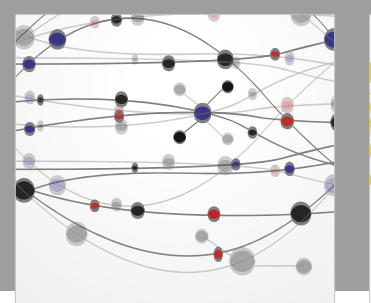

The Scientific World Journal

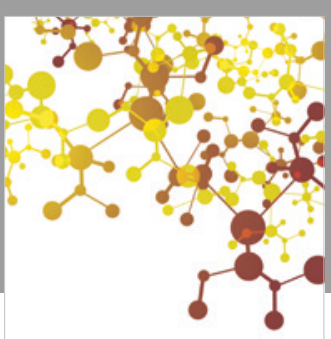

Journal of

Applied Chemistry
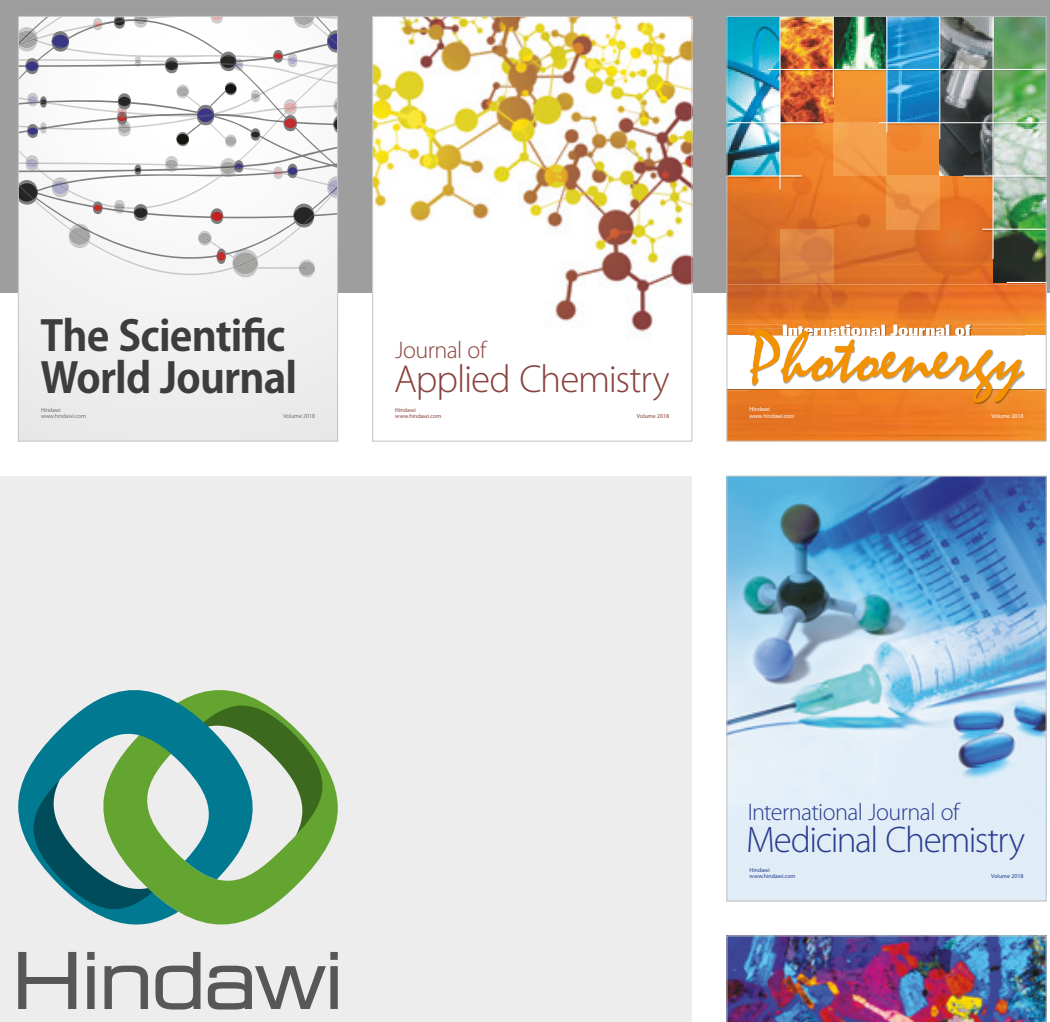

Submit your manuscripts at

www.hindawi.com
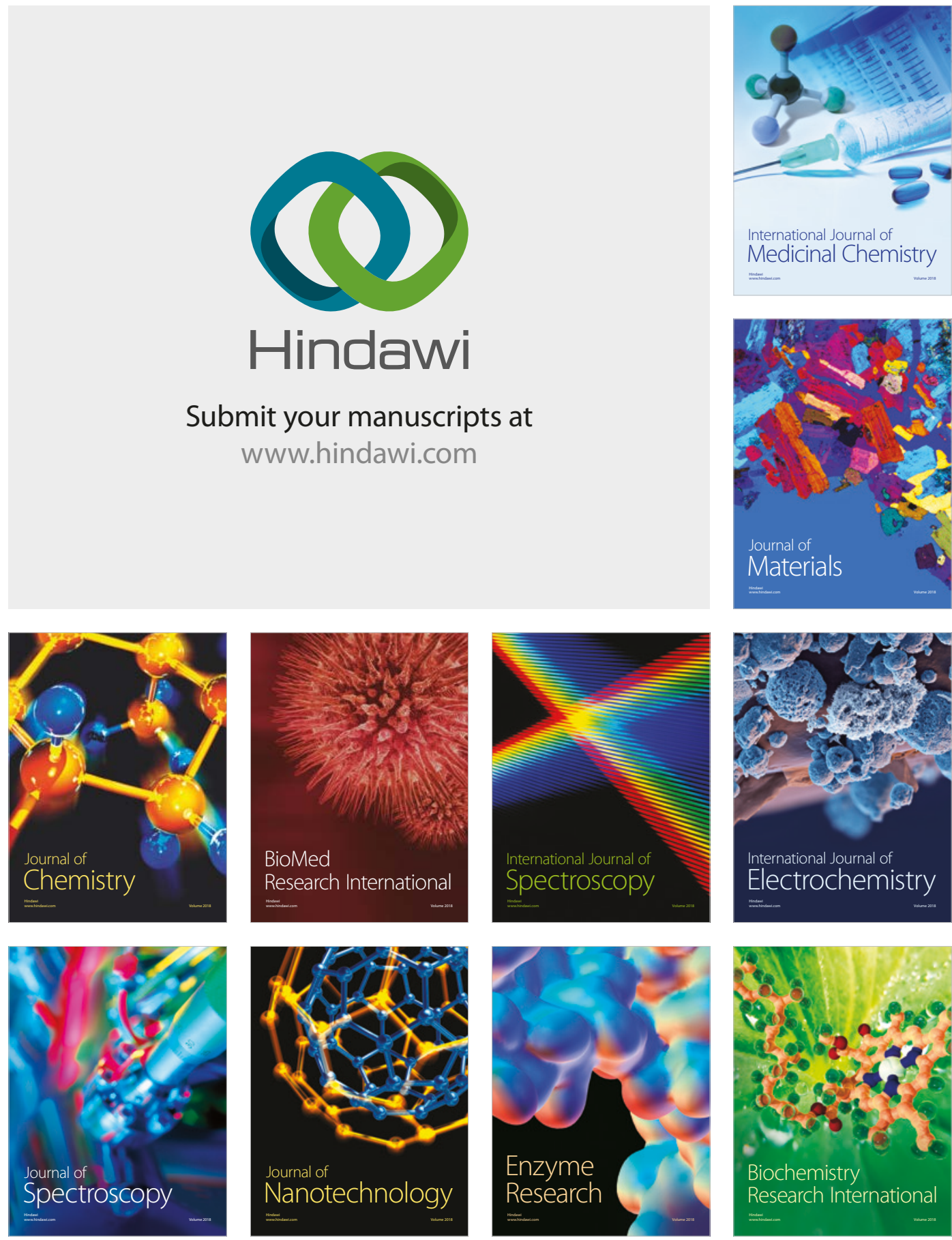
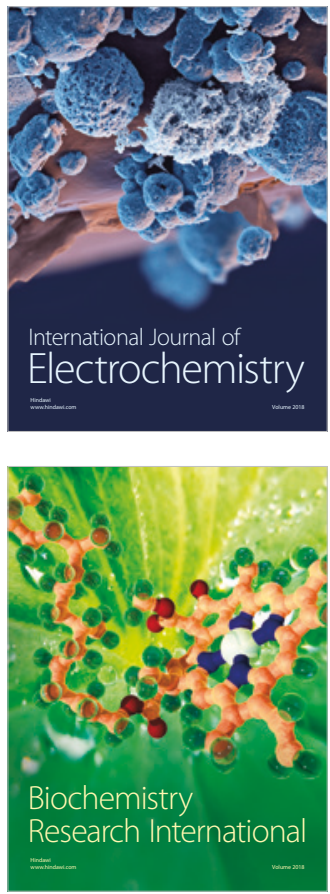